\title{
DESAIN ENCLOSURE AKUSTIK SEBAGAI MITIGASI POLUSI KEBISINGAN DI PEMBANGKIT LISTRIK MIKROHIDRO DAGO BENGKOK BANDUNG
}

\author{
SEPRIJAL BERLIANSYAH, DIDIN AGUSTIAN PERMADI \\ Program Studi Teknik Lingkungan, Fakultas Teknik Sipil dan Perencanaan \\ Institut Teknologi Nasional Bandung \\ Email : sefrizalberli@gmail.com
}

\begin{abstract}
ABSTRAK
Kebisingan industri merupakan gangguan suara yang diakibatkan terutama berasal dari operasional mesin, gangguan ini dapat mengganggu kesehatan dan performansi pekerja industri tersebut. Dari hasil pengukuran lapangan didapatkan nilai tingkat kebising 8 jam di ruang turbin-generator sebesar 92-99 dBA.. Dari perencanaan yang dilakukan untuk desain enclosure didapatkan spesifikasi enclosure yaitu menggunakan material plywood dengan ukuran $16 m \times 7 m \times 2,5 m$, diberi dua buah pintu akses ukuran $2 \mathrm{~m} \times 1 \mathrm{~m}$ menggunakan material plywood, didapatkan efektifitas penurunan tingkat kebisingan sebesar 38,07 dBA, sehingga didapatkan penurunan tingkat kebisingan setelah penggunaan enclosure di area turbin-generator menjadi 54-56 dBA. Total anggaran biaya yang dibutuhkan untuk membangun enclosure sebesar Rp 135.721.378,00.
\end{abstract}

Kata kunci : kebisingan; enclosure; turbin-generator

\begin{abstract}
Industrial noise is a sound disturbance that is caused mainly from machine operations, this disturbance can interfere with the health and performance of the industrial workers. From the results of field measurements, the 8 hours noise level in the turbine-generator room is 92-99 dBA. By applying the source-medium-receiver concept approach, it is known that one of the most effective techniques for controlling noise is by using an acoustic enclosure. From the planning carried out for the enclosure design, specifications are obtained, namely using plywood material with a size of $16 \mathrm{~m} \times 7 \mathrm{~m} \times 2.5 \mathrm{~m}$, the effectiveness of reducing noise levels is $38.07 \mathrm{dBA}$, resulting in a reduction in noise levels after using the enclosure in the turbine-generator area becomes 54$56 \mathrm{dBA}$. The total budget needed to build the enclosure is IDR 135,721,378
\end{abstract}

Keywords : noise; enclosure; turbine-generator 


\section{Pendahuluan}

Kegiatan proses operasional mesin-mesin di suatu industri dapat mempengaruhi kesehatan, keselamatan serta kenyamanan pekerja terutama pada mesin-mesin yang menghasilkan tingkat tekanan bunyi yang tinggi sehingga menimbulkan bising. Bising yang memiliki tingkat tekanan bunyi di atas nilai ambang batas akan mempengaruhi proses pendengaran dan proses komunikasi antar karyawan. Selain itu, bising yang terlalu berlebihan akan mengakibatkan terganggunya konsentrasi karyawan sehingga dapat menurunkan performansi pada pekerja.

Selain masalah - masalah teknis, PLTA Dago Bengkok secara konstruksi dan teknologi terbilang tua dimana pembangkit ini mulai beroperasi tahun 1927 atau hampir 100 tahun jika dibandingkan dengan PLTA modern, ada beberapa kendala dan masalah secara teknis dan operasi yang berpengaruh pada produksi dan lingkungan kerja termasuk kesehatan para pekerja. Menurut Putri (2018) bising atau Kebisingan di lingkungan kerja menjadi salah satu masalah pada kesehatan pekerja yang dapat berpengaruh secara psikologi dan performansi para pekerja.

Proses mekanis Pembangkit Listrik Tenaga Air (PLTA) dangan menggunakan turbin sebagai penggerak generator menyebabkan daya getar tinggi yang menghasilkan intensitas gelombang suara yang sangat keras. Hal tersebut akan meningkatkan pemaparan suara pada pekerja serta menambah resiko pada perkerja. Berdasarkan PERMENAKER No. PER. 13/MEN/X/2011 tentang Nilai Ambang Batas Faktor Fisika dan Faktor Kimia di Tempat Kerja, ambang batas kebisingan untuk pekerja adalah 85 dBA selama 8 jam. Jika pekerja terpapar kebisingan melebihi intensitas kebisingan dan waktu pajanan maka pekerja berpotensi mengalami gangguan kesehatan yang akan berpengaruh secara psikologis dan performansi. Pada penelitian ini, akan dilakukan pengendalian tingkat kebisngan pada ruang turbingenerator sebagai salah satu upaya dalam mengendalikan kebisingan sehingga tercipta suasana lingkungan kerja yang sehat serta nyaman pada pekerja. Menurut David A Bies (2003) jika suatu industri telah dibangun dan tidak memungkinkan untuk memodifikasi karakteristik sumber kebisingan maka, solusi yang memungkinkan pada masalah kebisingan adalah dengan memodifikasi jalur transmisi antara sumber kebisingan dengan penerima kebisingan tersebut. Enclosure menjadi salah satu alat pengendali kebisingan yang dapat mengatasi masalah kebisingan dengan memodifikasi transmisi akustik antara sumber kebisingan dengan penerima kebisingan.

\section{BAHAN DAN METODE}

\subsection{Pengukuran}

Pengumpulan data primer analisis kebisingan di ruang turbin-generator Dago Bengkok diperoleh dengan cara pengukuran menggunakan alat Sound Level Meter model SL-4012. Dengan spesifikasi 30-130 dB, Auto \& Manual Range, frequency \& time weighting meet IEC 61672 class 2, A \& C frequency weighting, fast/slow time weighting, Data hold, Peak hold, memory (max,min), AC output \& RS-232 Size : $268 \times 68 \times 29 \mathrm{~m}$.

Waktu pengukuran kebisingan dilakukan sesuai KepMenLH No 48 Tahun 1996 tentang Baku Tingkat Kebisingan dengan metode Cara Langsung, dilakukan pengukuran selama 10 (sepuluh) menit, sedangkan rentang waktu yang telah ditentukan yaitu per 1 menit. Waktu pengukuran dilakukan pada aktifitas kerja 8 jam (LS) dengan cara pada siang hari pada tingkat aktifitas yang paling tinggi selama 8 jam (LS) pada selang waktu 09.00 - 11.00. 
Pengukuran tingkat kebisingan tiap frekuensi dilakukan dengan Sound Level Meter yang diintegrasikan pada komputer yang sudah terpasang software TrueRTA.

\subsection{Tingkat Kebisingan}

Metoda Perhitungan mengacu pada SNI 7231:2009 tentang Metoda Pengukuran Intensitas Kebisingan di Tempat Kerja yaitu:

$$
\operatorname{Leq}(8 \mathrm{jam})=10 \log \left[\frac{1}{8}\left(\sum_{i=1}^{s} t i \cdot 10^{0,1 \cdot L 1}\right)\right]
$$

Keterangan :

Leq = Tingkat kebisingan siang hari ( $\mathrm{dBA})$

Lp $(A)=$ Tingkat tekanan bunyi pada pembobotan $A$

$\mathrm{t} \quad=$ Rentang waktu pengukuran $(\mathrm{dBA})$

\subsection{Pemetaan}

Pemetaan kebisingan dilakukan dengan metode Noise Mapping, metode ini berfungsi untuk mengetahui area mana saja yang memiliki nilai kebisingan diatas ambang batas maupun dibawah ambang batas yang diperbolehkan sesuai baku mutu dan persebaran kebisingan yang terjadi di gedung pembangkit PLTA Dago Bengkok. Hasil pemetaan berbentuk data digital yang dapat di cetak secara fisik.

\subsection{Desain Enclosure}

Perhitungan noise reduction berfungsi untuk mencari nilai TL (transmission loss). Nilai NR dapat dihitung dengan menggunakan persamaan berikut :

$$
N R=L p 1-L p 2
$$

Keterangan :

Lp1 = Tingkat kebisingan sumber $(\mathrm{dB})$

Lp2 = Tingkat kebisingan penerima $(\mathrm{dB})$

Perhitungan nilai TL berfungsi untuk menentukan nilai daya akustik dari sumber kebisingan (W), nilai TL dapat dihitung dengan persamaan :

$$
T L=10 \log \left(\frac{1}{4}+\frac{S w}{R}\right)-N R
$$

Jika diantara sumber kebisingan dengan penerima tidak memiliki penghalang atau panil maka TL bernilai nol. Maka persamaan menghitung TL akan menjadi berikut :

$$
T L=0
$$

Keterangan :

$\mathrm{TL} \quad=$ Transmission loss $(\mathrm{dB})$

$\mathrm{Sw}=$ Luas permukaan panil ruang penerima $\left(\mathrm{m}^{2}\right)$

$\mathrm{R} \quad=$ Konstanta ruang penerima

$\mathrm{NR} \quad=$ Noise Reduction $(\mathrm{dB})$ 
Nilai $\mathrm{W}$ berfungsi untuk menentukan material yang akan digunakan untuk perencanaan enclosure, nilai W dapat dihitung melalui persamaan sebagai berikut :

$$
T L=(20 \log W)+(20 \log f)-C
$$

Keterangan :

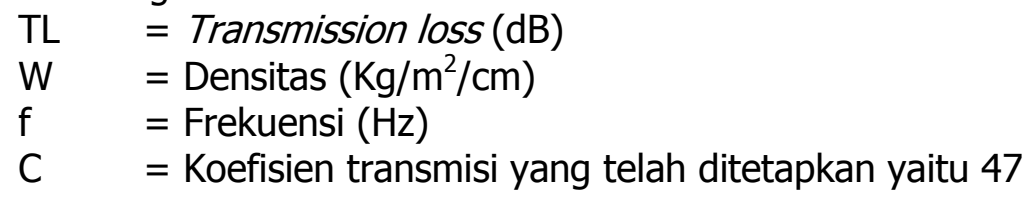

Nilai $\mathrm{W}$ yang paling besar pada frekuensi tertentu nantinya menjadi acuan pemilihan material pembuatan enclosure.

\subsection{Efektifitas Enclosure}

Nilai Lp2 adalah nilai tingkat kebisingan pada ruang penerima setelah pemasangan enclosure pada sumber kebisingan, nilai Lp2 dapat dihitung dengan persamaan sebagai berikut :

$$
L p 2=L p 1-T L+10 \log \left(\frac{1}{4}+\frac{S w}{R}\right)
$$

Keterangan :

$\mathrm{NR}=$ Noise reduction $(\mathrm{dB})$

Lp1 = Tingkat kebisingan sumber $(\mathrm{dB})$

Lp2 = Tingkat kebisingan penerima $(\mathrm{dB})$

$\mathrm{TL} \quad=$ Transmission loss $(\mathrm{dB})$

$\mathrm{Sw}=$ Luas panil penerima $\left(\mathrm{m}^{2}\right)$

$\mathrm{R} \quad=$ Konstantan ruang penerima

Nilai Lp2 yang didapatkan selanjutnya di konversi kembali dari dB ke dBA. Untuk mengetahui berapa tingkat kebisingan ruang penerima yang berkurang setelah sumber kebisingan dienclosure dilakukan perhitungan dengan persamaan sebagai berikut :

$$
I L=L p 2 \text { sebelum }- \text { Lp2 sesudah }
$$

Keterangan :

IL $\quad=$ Penurunan tingkat kebisingan (dBA)

Lp2 sebelum = Leq penerima sebelum di-enclosure $(\mathrm{dBA})$

Lp2 sesudah = Leq penerima sesudah di-enclosure $(\mathrm{dBA})$

Nilai Lp2 sesudah Enclosure di targetkan dibawah nilai baku mutu kebisingan yang ditetapkan oleh Permenaker No.13 Tahun 2011.

\subsection{Rencana Anggaran Biaya}

Setelah jenis konstruksi, gambar desain dan perhitungan maka dibuat rancangan anggaran biaya untuk mengetahui banyaknya biaya yang diperlukan untuk membeli bahan, alat dan upah, serta biaya-biaya lain yang berhubungan dengan pelaksanaan pekerjaan atau proyek tersebut (Tri Joko, 2018). 


\section{HASIL DAN PEMBAHASAN}

\subsection{Hasil Pengukuran}

Untuk memperoleh Leq 8 jam maka dilakukan perhitungan dengan persamaan yang mengacu pada SNI 7231:2009 tentang Metode Pengukuran Intensitas Kebisingan di Tempat Kerja disetiap titik digunakan untuk membuat peta persebaran kebisingan pada gedung pembangkit PLTA Dago Bengkok. Berikut rekapitulasi hasil perhitungan Leq 8 jam yang dapat dilihat pada Tabel 1:

Tabel 1. Rekapitulasi Hasil Perhitungan Leq 10 Menit dan 8 Jam

\begin{tabular}{ccc}
\hline $\begin{array}{c}\text { No } \\
\text { Titik }\end{array}$ & Leq 10 Menit (dBA) & Leq 8 Jam (dBA) \\
\hline $\mathbf{1}$ & 74,65 & 83,03 \\
\hline $\mathbf{2}$ & 84,38 & 92,76 \\
\hline $\mathbf{3}$ & 68,36 & 76,73 \\
\hline $\mathbf{4}$ & 75,65 & 84,03 \\
\hline $\mathbf{5}$ & 91,10 & 99,47 \\
\hline $\mathbf{6}$ & 84,38 & 92,75 \\
\hline $\mathbf{7}$ & 67,34 & 75,71 \\
\hline $\mathbf{8}$ & 64,43 & 72,81 \\
\hline $\mathbf{9}$ & 81,23 & 89,61 \\
\hline $\mathbf{1 0}$ & 86,57 & 94,94 \\
\hline $\mathbf{1 1}$ & 84,44 & 92,81 \\
\hline $\mathbf{1 2}$ & 68,44 & 76,81 \\
\hline $\mathbf{1 3}$ & 63,45 & 71,82 \\
\hline $\mathbf{1 4}$ & 54,30 & 62,68 \\
\hline $\mathbf{1 5}$ & 62,35 & 70,72 \\
\hline $\mathbf{1 6}$ & 60,41 & 68,78 \\
\hline $\mathbf{1 7}$ & 64,34 & 72,71 \\
\hline $\mathbf{1 8}$ & 57,36 & 65,74 \\
\hline $\mathbf{1 9}$ & 58,45 & 66,82 \\
\hline $\mathbf{2 0}$ & 60,35 & 68,73 \\
\hline $\mathbf{2 1}$ & 57,29 & 65,67 \\
\hline $\mathbf{2 2}$ & 58,64 & 67,02 \\
\hline $\mathbf{2 3}$ & 60,36 & 68,73 \\
\hline $\mathbf{2 4}$ & 56,43 & 64,80 \\
\hline & & \\
\hline
\end{tabular}

Dilihat dari Tabel 1 titik dengan nilai Leq paling tinggi adalah pada titik 5, dengan nilai Leq 99,47 dBA, titik 5 adalah ruang turbin-generator beroperasi, turbin-generator pada gedung pembangkit PLTA Dago Bengkok merupakan sumber utama kebisingan sehingga diperlukan pengendalian kebisingan.

\subsection{Hasil Pemetaan}

Pemetaan tingkat kebisingan dilakukan untuk menentukan apakah tingkat kebisingan yang dihasilkan oleh industri tidak melebihi baku mutu yang mengacu pada regulasi yang ditetapkan oleh Peraturan Menteri Tenaga Kerja dan Transmigrasi Republik Indonesia No. 13 Tahun 2011 tentang Nilai Ambang Batas Faktor Fisika dan Faktor Kimia di Tempat Kerja. Berikut ini adalah hasil peta kontur yang dihasilkan oleh input data $x, y, z$ pada software Golden Surfer 13 : 


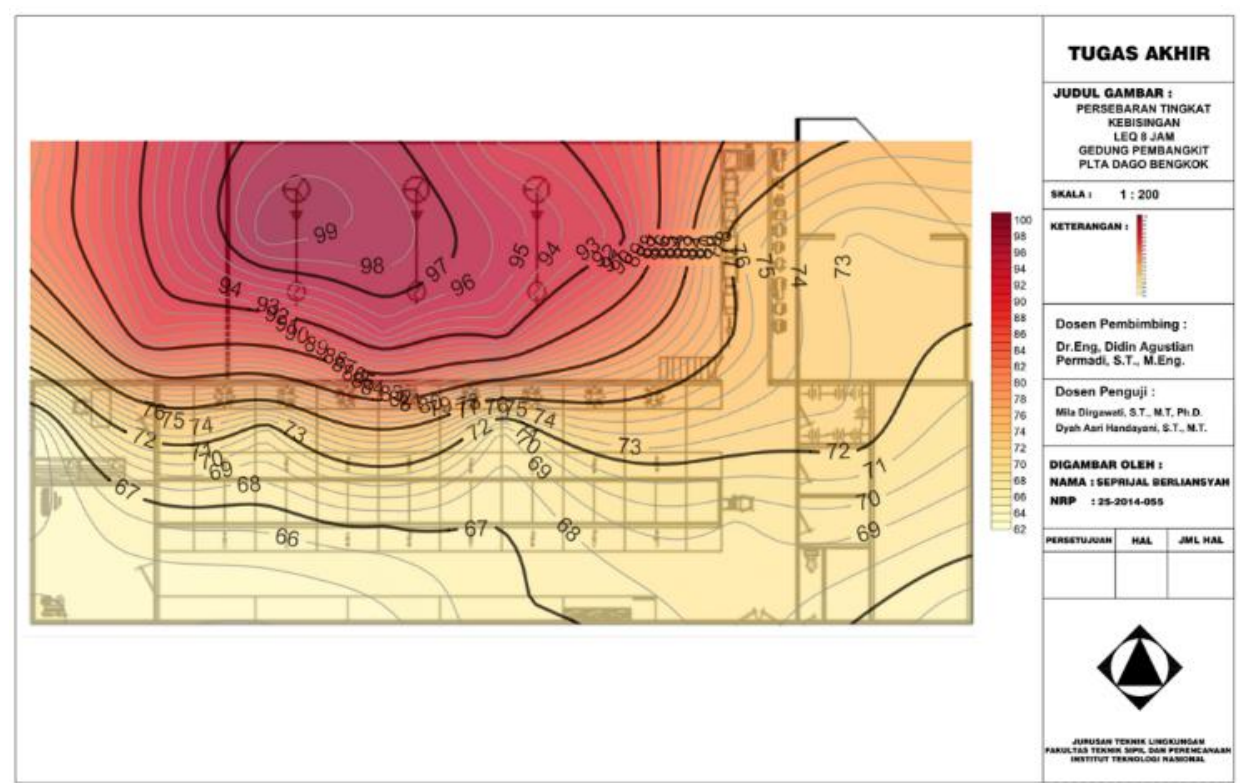

Gambar 1. Persebaran Tingkat Kebisingan Leq 8 Jam

Pada hasil pemetaan dapat dilihat hasil persebaran nilai Leq 8 jam yang dihasilkan cenderung lebih kecil di sekitar ruang turbin-generator. Perbedaan nilai yang diukur dan yang dihitung cukup signifikan perbedaannya. Ini menunjukan bahwa tingkat kebisingan sesaat berbeda dengan tingkat kebisingan ekivalen. Kebisingan yang terjadi di ruang turbingenerator berkisar antara 86-99 dB(A), ruangan ini adalah sumber utama kebisingan di gedung pembangkit PLTA Dago Bengkok. Berdasarkan Gambar 1 bahwa ruangan yang melebihi baku mutu adalah ruangan turbin-generator, ruangan turbin-generator yang melebihi nilai ambang batas kebisingan perlu dilakukan pengendalian.

\subsection{Desain Enclosure}

Pada penelitian ini, nilai kerapatan massa jenis (W) merupakan suatu nilai yang digunakan untuk menentukan bahan yang akan digunakan untuk rancangan enclosure. Tabel 2 menunjukkan nilai $\mathrm{W}$ pada ruang turbin-generator

Tabel 2. Rekapitulasi Perhitungan Penentuan Nilai w

\begin{tabular}{cccccc}
\hline $\mathbf{F}(\mathbf{H z})$ & $\mathbf{L P 1}(\mathbf{d B})$ & $\mathbf{L P 2}(\mathbf{d B})$ & $\mathbf{N R}(\mathbf{d B})$ & $\mathbf{T L}(\mathbf{d B})$ & $\mathbf{W}$ \\
\hline 125 & 76,5 & 69,6 & 6,9 & 0 & 1,79 \\
\hline 250 & 78,7 & 60,1 & 18,6 & 0 & 0,90 \\
\hline 500 & 79,6 & 65,2 & 14,4 & 0 & 0,45 \\
\hline 1000 & 79,4 & 77,1 & 2,3 & 0 & 0,22 \\
\hline 2000 & 80,4 & 77,5 & 2,9 & 0 & 0,11 \\
\hline 4000 & 86,7 & 78,5 & 8,2 & 0 & 0,06 \\
\hline
\end{tabular}

Dari Tabel 2 didapatkan nilai $W$ tertinggi pada frekuensi $125 \mathrm{~Hz}$ sebesar $1,79 \mathrm{Kg} / \mathrm{m}^{2} / \mathrm{cm}$. mengacu pada tabel material, bahan yang akan digunakan untuk pembuatan enclosure adalah Plywood dengan ketebalan minimal $25 \mathrm{~mm}$. Adapun material lain yang digunakan untuk pembuatan enclosure adalah kayu dengan ketebalan minimal $25 \mathrm{~mm}$ sebagai pintu akses memasuki unit turbin-generator dan kaca sebagai jendela pengamatan dengan ketebalan $12 \mathrm{~mm}$. 
Akses pintu pada enclosure yang di desain untuk gedung pembangkit PLTA Dago Bengkok memiliki spesifikasi menggunakan material plywood ukuran $1 \mathrm{~m} \times 2 \mathrm{~m}$ dengan ketebalan 3,5 $\mathrm{cm}$ beserta kelengkapannya antara lain piano hinge, segel karet, positive-pressure latch.

Kaca jendela yang di-desain pada enclosure PLTA Dago Bengkok memiliki spesifikasi yaitu menggunakan material plate acrylic berukuran $1 \mathrm{~m} \times 1,5 \mathrm{~m}$ dengan ketebalan $1,5 \mathrm{~cm}$ beserta kelengkapannya antara lain rubber gasket, 90 degree glass clamp, dan sekrup 16 $\mathrm{mm}$.

Sistem udara dibutuhkan untuk menyediakan akses ventilasi pada enclosure, setidaknya 1 air change per minute (ACPM). Sound trap atau perangkap suara juga dibutuhkan pada intake dan exhaust udara. Fan atau kipas yang digunakan menggunakan merk KCK model 40-SGC yang memiliki spesifikasi yaitu frekuensi $50 \mathrm{~Hz}$, daya listrik 161 Watt, kecepatan motor 1450 $\mathrm{RPM}$, volume udara $3610 \mathrm{CMH}$, tingkat tekanan suara 46,5 dB, dan berat $19 \mathrm{Kg}$

Sistem ventilasi enclosure pada PLTA Dago Bengkok dibutuhkan sound trap atau perangkap suara. sound trap ventilasi pada enclosure PLTA Dago Bengkok memiliki ukuran $150 \mathrm{~cm} \times 60$ $\mathrm{cm}$ x $58 \mathrm{~cm}$, menggunakan material luar berupa plywood dan material dalam menggunakan polyurethane foam.

Dari hasil perhitungan suplai udara per menit kemampuan kipas, didapatkan nilai suplai udara per menit per 1 (satu) kipas adalah sebesar 0,215 ACPM. Sedangkan untuk memenuhi nilai kebutuhan 1 ACPM dibutuhkan 4 tambahan kipas menjadi 5 kipas untuk exhaust dan 5 kipas untuk intake agar memenuhi kebutuhan suplai udara pada enclosure. Sehingga kebutuhan kipas yang digunakan adalah sebanyak 10 buah.

Enclosure yang di desain termasuk kedalam enclosure yang besar. Dengan ukuran $16 \mathrm{~m} \times 7$ $\mathrm{m} \times 2,5 \mathrm{~m}$. Hasil desain dan konstruki enclosure dan utilitasnya digambarkan pada Gambar 2 berikut :

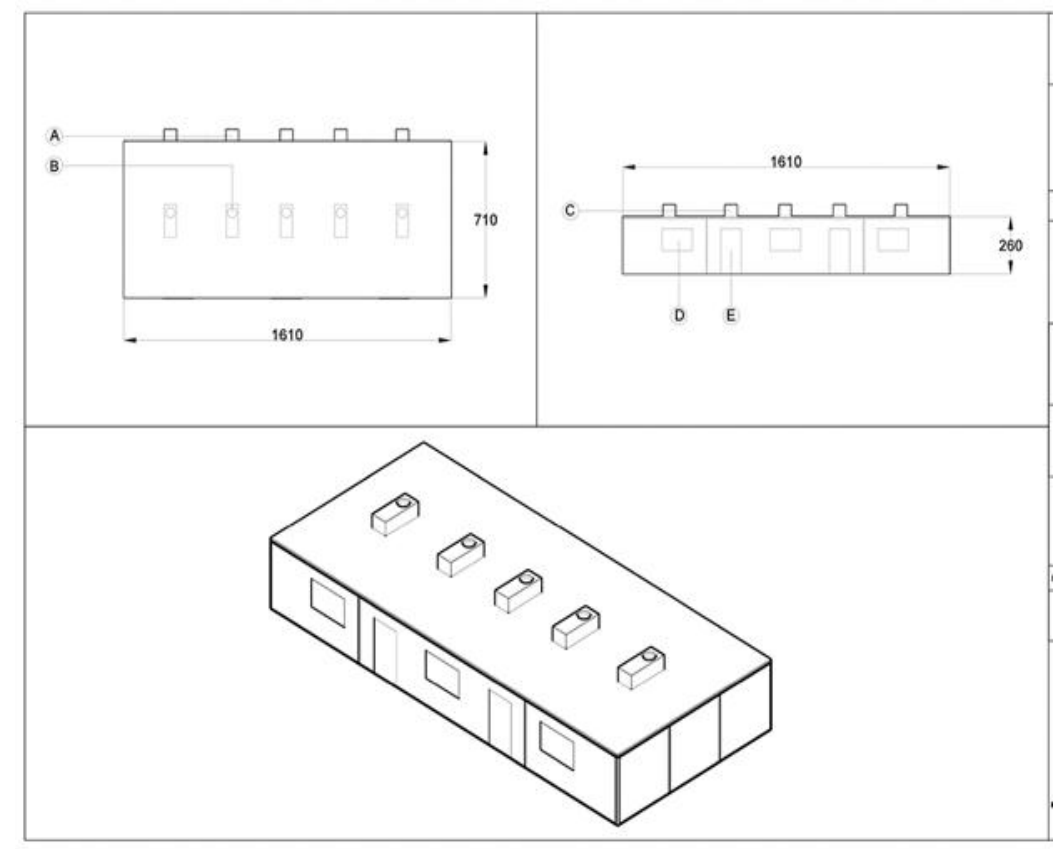

Gambar 2. Desain Enclosure PLTA Dago Bengkok 


\subsection{Efektivitas Enclosure}

Insertion loss (IL) atau nilai pengurangan kebisingan yang terjadi setelah enclosure berfungsi untuk mengetahui efektifitas dari pemasangan enclosure pada unit turbingenerator. Berikut rekapitulasi data perhitungan mencari nilai IL pada ruang turbin-generator PLTA Dago Bengkok setelah di-enclosure pada tiap frekuensi :

Tabel 3. Rekapitulasi Perhitungan Nilai IL

\begin{tabular}{|c|c|c|c|c|c|c|c|c|}
\hline$F$ & Lp1 (dB) & $\begin{array}{l}\text { Lp2 } \\
\text { Awal } \\
\text { (dB) }\end{array}$ & á & $\mathbf{R}$ & Sw $\left(m^{2}\right)$ & So $\left(m^{2}\right)$ & SPL 2 (dB) & IL (dB) \\
\hline 125 & 76,5 & 69,6 & 0,141 & 112,97 & \multirow{6}{*}{169,5} & \multirow{6}{*}{686,8} & 50,07 & 26,43 \\
\hline 250 & 78,7 & 60,1 & 0,119 & 93,12 & & & 53,54 & 25,16 \\
\hline 500 & 79,6 & 65,2 & 0,103 & 78,83 & & & 48,80 & 30,80 \\
\hline 1000 & 79,4 & 77,1 & 0,087 & 65,36 & & & 46,86 & 32,54 \\
\hline 2000 & 80,4 & 77,5 & 0,077 & 57,28 & & & 51,54 & 30,06 \\
\hline 4000 & 86,7 & 78,5 & 0,076 & 56,30 & & & 55,57 & 32,13 \\
\hline Overall & 89,42 & 82,83 & & & & & 59,27 & 38,07 \\
\hline
\end{tabular}

Dari Tabel 3 didapatkan hasil nilai IL atau kemampuan enclosure menahan kebisingan yang di hasilkan oleh turbin-generator di setiap frekuensi, nilai pengurangan tingkat kebisingan setelah di-enclosure bervariasi di setiap frekuensi dari 25,16 dB hingga 32,54 dB dengan nilai ekivalen sebesar 38,07 dB. Gambar 3 merupakan perbandingan tingkat kebisingan setelah menggunakan enclosure:

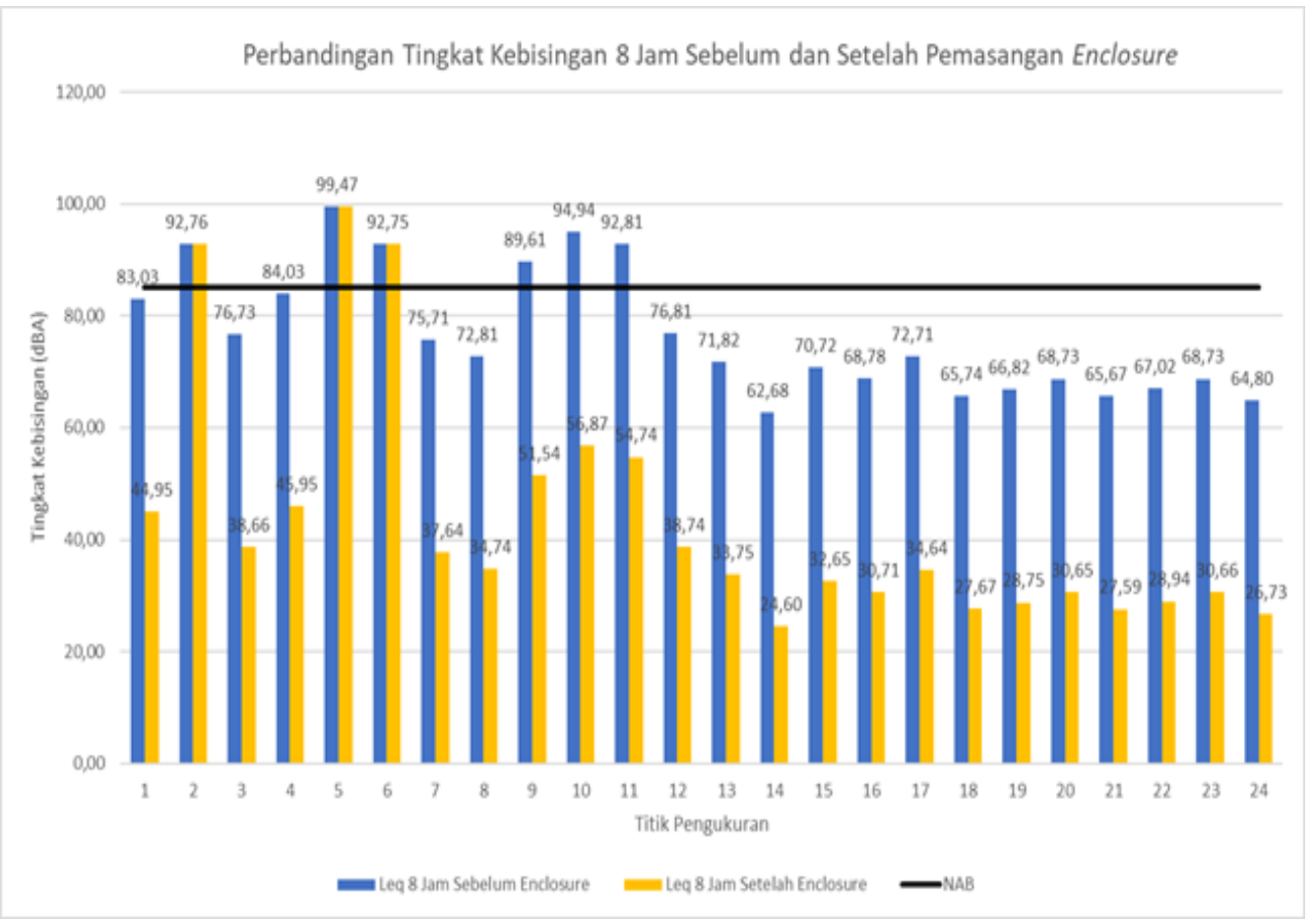

Gambar 3. Grafik Perbandingan Leq 8 Jam Sebelum dan Sesudah Pemasangan Enclosure 
Tabel 4. Rencana Anggaran Biaya Pembuatan Enclosure

\begin{tabular}{|c|c|c|c|c|c|}
\hline No & Uraian Pekerjaan & Ukuran & Satuan & Harga Satuan (Rp) & Jumlah Harga (Rp) \\
\hline I & BANGUNAN ENCLOSURE & & & & \\
\hline 1 & Plywood (birch) & 227 & $\mathrm{~m}^{2}$ & 136.467 & 30.978 .009 \\
\hline 2 & Aluminium frame & 171 & $\mathrm{~m}$ & 238.538 & 40.759 .218 \\
\hline 3 & Baut & $16 \times 60$ & $\mathrm{~mm}$ & 25.000 & 2.875 .000 \\
\hline II & JENDELA & & & & \\
\hline 1 & Plate acrylic & $1,5 \times 1$ & $\mathrm{~m}$ & 91.676 & 412.542 \\
\hline 2 & Baut & $16 \times 60$ & $\mathrm{~mm}$ & 25.000 & 300.000 \\
\hline 3 & Rubber gasket & $100 \times 100$ & $\mathrm{~cm}$ & 595.000 & 803.250 \\
\hline 4 & Klem stainless steel & $48 \times 45$ & $\mathrm{~mm}$ & 186.240 & 2.979 .840 \\
\hline IV & PINTU AKSES & & & & \\
\hline 1 & Plywood (albasia) & $1 \times 2$ & $\mathrm{~m}$ & 175.000 & 350.000 \\
\hline 2 & Piano hinge continous & 60 & $\mathrm{~cm}$ & 284.471 & 568.942 \\
\hline 3 & Rubber gasket & $100 \times 100$ & $\mathrm{~cm}$ & 595.000 & 595.000 \\
\hline 4 & Positive cam type latch & $31 \times 27 \times 21$ & $\mathrm{~cm}$ & 260.924 & 260.924 \\
\hline III & SISTEM VENTILASI & & & & \\
\hline 1 & Kipas & 16 & inch & 4.767 .000 & 47.670 .000 \\
\hline 2 & Plywood (birch) & 45 & $m^{2}$ & 136.467 & 6.141 .015 \\
\hline 3 & Polyurethane foam & 45 & $m^{2}$ & 14.104 & 634.680 \\
\hline IV & PENETRASI & & & & \\
\hline 1 & PVC Conduit & 50 & $\mathrm{~m}$ & 4.700 & 235.000 \\
\hline 2 & Lead sheet & 1 & $m^{2}$ & 157.958 & 157.958 \\
\hline \multicolumn{2}{|c|}{ BIAYA KESELURUHAN } & & & & 135.721 .378 \\
\hline
\end{tabular}

\section{KESIMPULAN}

Dari hasil dan pembahasan tingkat kebisingan di PLTA Dago Bengkok Bandung, maka dapat disimpulkan bahwa tingkat kebisingan 8 jam hasil perhitungan menurut SNI 7231:2009 didapatkan hasil sebesar antara 62,68-99,47 dBA. Dari hasil perhitungan tersebut titik pengukuran 2, 5, 6, 10, dan 11 melebihi baku mutu menurut PERMENAKER No. PER. 13/MEN/X/2011 yaitu sebesar $85 \mathrm{dBA}$ selama 8 jam. Dari hasil evaluasi model pemetaan menggunakan program surfer. Tingkat kebisingan yang melebihi baku mutu berada di ruang turbin-generator yaitu berkisar antara 86-99 dBA. Konstruksi enclosure di desain menggunakan material plywood dengan ukuran total $16 \mathrm{~m} \times 7 \mathrm{~m} \times 2,5 \mathrm{~m}$ diberi 2 buah pintu yang berukuran $1 \mathrm{~m} \times 2 \mathrm{~m}$ menggunakan material kayu plywood albasia, jendela 3 buah dengan ukuran $1 \mathrm{~m} \times 1,5 \mathrm{~m}$ menggunakan material plate acrylic, sistem ventilasi menggunakan kipas dengan kapasitas $3610 \mathrm{CMH}$ dilengkapi dengan perangkap suara berukuran $150 \mathrm{~cm}$ x $60 \mathrm{~cm}$ x $58 \mathrm{~cm}$ menggunakan material plywood dan polyurethane foam, serta penangan penetrasi menggunakan lead sheet. Dari hasil perhitungan nilai insertion loss (IL) atau kemampuan enclosure mengurangi tekanan suara yang dihasilkan didapatkan nilai sebesar 38,07 dB.

\section{UCAPAN TERIMA KASIH}

Peneliti menyampaikan terima kasih kepada bapak Rochmat Selamet dan PT Indonesia Power Sub Unit PLTA Bengkok atas dukungannya selama penelitian dengan memberikan data pendukung mengenai penelitian ini.

\section{DAFTAR RUJUKAN}

Barron, R. F. (2001). Industrial Noise Control and Acoustic. Ruston: Marcel Dekker, inc. 
Bell, L. H. (1994). Industrial Noise Control (2nd ed.). New York: Marcel Dekker, Inc.

Beranek, L. L., \& Ver, I. L. (2006). Noise and Vibration Control Engineering (2nd ed.). New Jersey: John Wiley \& Sons, Inc.

Bies, D. A., \& Hansen, C. H. (1996). Engineering Noise Control (2nd ed.). London: Spon Press.

Brüel \& Kjær Sound \& Vibration Measurement A/S. (2001). Environmental Noise. Nærum: Brüel \& Kjær Sound \& Vibration Measurement A/S.

Committee on Industrial Ventilation. (1998). Industrial Ventilation (23rd ed.). Ohio: American Conference of Governmental Industrial Hygienists, Inc.

Joko, T. (2018, Desember). Rencana Anggaran Biaya. Kendari, Sulawesi Tenggara, Indonesia: Kementrian Pekerjaan Umum dan Perumahan Rakyat.

Kinsler, L. E., Frey, A. R., Coppens, A. B., \& Sanders, J. V. (2000). Fundamental of Acoustics (4th ed.). New York: John Wiley \& Sons, Inc.

Komrower, J. (2015). Engineering Controls for Hydroelectric Powerplant Noise Reduction. Denver: The U.S. Department of the Interior.

Peterson, A. P. (1980). Handbook of Noise Measurement (9th ed.). Massachusetts: GenRad, Inc.

Putri, K. F., Anindita, G., \& Santoso, M. Y. (2018). Perancangan Enclosure Ruang Wattable Powder Plant pada Perusahaan Pembuat Pestisida. Proceeding 2nd Conference On Safety Engineering, 1-2.

Shepherd, K. P. (1981). Handbook for Industrial Noise Control. Hampton: National Aeronautics and Space Administration. 